\title{
Ensino de Geografia, Educação Rural e Educação do Campo: Modernidade, Subalternidade e Resistência.
}

Tássia Gabriele Balbi de Figueiredo e Cordeiro ${ }^{1}$

UERJ/FFP

\section{Resumo}

Refletiremos neste artigo acerca de como o ensino de geografia é ministrado nas escolas rurais, para tanto relacionaremos a geografia escolar com o paradigma da educação rural, assim como apresentaremos a possibilidade de construção de um novo paradigma contra-hegemônico, a educação do campo. Esta relação entre a educação rural e o ensino de geografia, é vista por nós como pautada pelo paradigma moderno, que com seus ideais coloniais e eurocêntricos de dominação teria fomentado uma educação urbanocêntrica para as escolas rurais. Por fim, refletiremos sobre a possibilidade de um ensino de geografia articulado à construção de uma educação verdadeiramente do campo, questionando: uma geografia do campo é possível?

Palavras-chave: educação rural, educação do campo, ensino de geografia e modernidade.

\section{Resumen}

Reflexionaremos en este artículo sobre como la enseñanza de geografia es ministrada en lãs escuelas rurales, para eso relacionaremos la geografia escolar con el paradigma de la educación rural, así como presentaremos la posibilidad de construcción de un nuevo paradigma contra-hegemónico, la educación del campo. Esta relación entre la educación rural y la enseñanza de geografia es vista por nosotros como pautada por el paradigma moderno, que con sus ideales coloniales y eurocéntricos de dominación habria fomentado una educación urbanocéntrica para las escuelas rurales. Por fin, reflexionaremos sobre la posibilidad de una enseñanza de geografia articulada a la construcción de una educación verdaderamente del campo, cuestionando: ¿es posible una geografia del campo?

Palabras clave: educación rural, educación de campo, enseñanza de la geografia y modernidad. 


\section{Introdução}

"O conhecimento cientifico só o é na medida em que for ataque e confrontação. Só existe ciência enquanto crítica da realidade a partir da realidade que existe e com vista a sua transformação em uma outra realidade"

Boaventura de Souza Santos

$\mathrm{Na}$ elaboração desta pesquisa entendemos que a ciência tem um papel político de serviço à sociedade, papel este condizente com as palavras de Boaventura. Porém reconhecemos que epistemologicamente a ciência não serviu aos interesses da maior parcela da sociedade, já que não assumiu o potencial político e ideológico de suas pesquisas, muito menos visou a transformação das realidades existentes, ao contrário, contribuiu fomentando e legitimando o colonialismo, a dominação e a exclusão, ou seja, a manutenção do Status Quo.

Deste modo, deixamos claro que a prática científica aqui proposta é uma prática pautada na confrontação e reflexão das realidades existentes nas escolas rurais brasileiras, com vistas a estimular o debate acerca da necessidade de transformação das mesmas, da necessidade de comprometimento com o devir, e com nossa parcela de responsabilidade no quefazer (FREIRE, 2005) diário no ensino de geografia.

Esta realidade a ser transformada diz respeito à contribuição da geografia escolar tradicional na reprodução dos ideários modernos, que, em nosso entendimento, fomentou o surgimento e a manutenção do paradigma da educação rural. Procuraremos compreender como este paradigma moderno influenciou o ensino de geografia fundamentado a partir de pressupostos coloniais, por isso mesmo, eurocêntricos, racistas, deterministas e urbanocêntricos, fomentando um currículo e uma prática docente neutralizadora e silenciadora do Outro, do subalterno, neste caso o campesinato e os trabalhadores e trabalhadoras rurais em geral. Dessa forma investigaremos até que ponto os currículos de geografia praticados foram agentes invisibilizadores da especificidade rural.

Consideramos que a questão apresentada tem um potencial político e ideológico de negação e silenciamento de identidades campesinas extremamente relacionada ao ensino de geografia e aos ideais reprodutivistas em educação. Entretanto, acreditamos ser papel dos geógrafos, como muito bem disse o geógrafo anarquista Piotr Kropotkin (1986, p. 5), "contrabalancear as influências hostis [...] e criar outros sentimentos mais dignos e humanos". Essas palavras sintetizam bem as motivações para a problematização deste tema.

Para tanto recorreremos a uma metodologia de revisão bibliográfica acerca das categorias de educação rural e de educação do campo, do paradigma moderno 
e do ensino de geografia, além da pesquisa de fontes legislativas, como a Lei de Diretrizes e Bases da Educação Nacional e as Diretrizes Operacionais para a Educação Básica nas Escolas do Campo. Para relacionarmos a ideologia moderna da educação rural e o ensino de geografia pesquisaremos livros didáticos de geografia aprovados pelo PNLD/MEC com alguns conteúdos que exemplifiquem a relação entre a educação rural e o ensino de geografia.

Primeiramente esclareceremos as diferenças entre a categoria educação rural e a construção da categoria educação do campo por parte dos movimentos sociais rurais brasileiros. Em um segundo momento, aprofundaremos a estreita relação entre a educação rural e o paradigma moderno, assim como a relação entre estes e o ensino de geografia, utilizando a análise dos livros didáticos. Finalizaremos a questão problematizando a possibilidade de uma geografia acadêmica e escolar comprometida com os povos e as lutas do campo.

\section{Da Educação Rural á luta pela Educação do Campo}

A desobediência e rebeldia (CALDART, 2004) dos povos do campo ${ }^{2}$ de nosso país, cansados da crueldade do sistema econômico capitalista globalizado, excludente e subalternizador, fez com que estes, a partir de uma ousadia, deixassem de se curvar diante da opressão, resolvendo assim, desobedecer e se rebelar diante da (des)ordem dominante. Uma das instituições mais idolatradas do nosso sistema foi alvo destas críticas: a escola. E é da revolta em relação a esta instituição e do ensino de geografia ministrado na mesma que refletiremos e, de acordo com nossas possibilidades, confrontaremos.

Porém, este confronto em relação à escola não questiona a necessidade e legitimidade desta instituição para nossa sociedade e sim o caráter reprodutor do próprio sistema capitalista, de sua ideologia, de seus interesses, dentro da escola, através, por exemplo, de sua pedagogia e de seu currículo. Desta forma a educação oferecida obrigatoriamente às nossas crianças serviria aos interesses das classes dominantes e não aos interesses da classe trabalhadora, entre eles o campesinato.

A classe dominante do campo brasileiro forma a oligarquia rural presente em outras esferas econômicas, inclusive na esfera política, formuladora de leis e políticas públicas para a educação. Este fato influencia toda a política brasileira e pode ser creditado tanto ao peso dos Complexos Agroindustriais quanto aos resquícios do coronelismo, que deixou seus herdeiros políticos e econômicos. Consequentemente, a educação oferecida nas escolas de áreas rurais reproduziria os conhecimentos necessários para a perpetuação da atual estrutura do campo brasileiro, onde predominam desde a exclusão do acesso à terra até mesmo o trabalho escravo contemporâneo. Estes interesses são transmitidos não só pela estrutura escolar como um todo, como também pelos conteúdos ministrados pelas 


\section{REVISTA TAMOIOS}

disciplinas, que formam o currículo, mas principalmente pelo currículo denominado oculto, ou seja, esta reprodução se dá, também, em um âmbito subjetivo.

Denominamos esta educação, reprodutora dos interesses ruralistas, de paradigma da educação rural, que norteou e ainda norteia, conscientemente ou não, grande parte das escolas rurais de nosso país, e se baseia, principalmente, na inferiorização e subalternização da vida rural e dos povos camponeses. Segundo Fernandes e Molina (2004, p. 62) "a origem da educação rural está na base do pensamento latifundista empresarial, do assistencialismo, do controle político sobre a terra e as pessoas que nela vivem".

$E$ até pouco tempo esta educação não havia sido contestada já que "A imagem que sempre temos na academia, na política, nos governos é que para a escolinha rural qualquer coisa serve. Para mexer com a enxada não há necessidade de muitas letras." (ARROYO, CALDART, MOLINA, 2004, p. 71), ou seja, ainda persiste a ideia de que para se trabalhar no campo não é necessário conhecimento, escolarização, e não podemos subestimar o caráter ideológico desta afirmação, onde o papel da escolinha não seria somente o das primeiras letras e sim a domesticação dos futuros trabalhadores rurais, posseiros, arrendatários, camponeses e sem-terras, que não deveriam lutar por dignidade e sim aceitar, aceitar, e quando não fosse mais possível aceitar, a única alternativa encontrada seria o êxodo rural.

Porém, é de interesse do paradigma da educação rural diminuir este êxodo em prol da permanência da "normalidade" da vida urbana. Esta afirmação baseia-se na própria formulação de leis e políticas públicas para as escolas rurais que quando tornadas, tardiamente, responsabilidade do Estado tiveram como um dos objetivos a contenção do êxodo, sem deixar de ser marginalizada quando comparada à escolarização urbana.

Segundo Leite:

Mesmo a república - sob inspiração positivista/cientificista não procurou desenvolver uma política educacional destinada à escolarização rural [...] a sociedade brasileira somente despertou para a educação rural por ocasião do forte movimento migratório interno dos anos 1910/20. (LEITE, 2002, p.28)

Lopes reflete sobre as consequências da urbanocentralidade da educação no Brasil sobre o estudante de escolas rurais ao afirmar que

a escola, no lugar de proporciona-lhe um campo de reflexão sobre sua vida de camponês, acaba impondo-lhe um modelo urbano, que o domina, transmitindo-lhe um saber reforçador de uma estrutura de desigualdade e de divisão entre homens cultos (da cidade) e homens incultos (roceiros). (LOPES apud LEITE, 2002, p. 84) 
Assim sendo, entendemos que o paradigma da educação rural proporcionou e legitimou uma visão depreciativa do campo e dos camponeses e camponesas, já que privilegiou uma visão de mundo, um lócus de enunciação urbanocêntrico, onde a urbanidade sempre foi apresentada como um modelo hierarquicamente superior, como sinônimo de evolução enquanto o campo, o lugar do campesinato, foi incisivamente apresentado e julgado como sinônimo de atraso. E a população rural não foi poupada do processo de inferiorização, foi e ainda é sistematicamente caricaturizada, ou seja, ridicularizada, não só pela escola, como também pelos meios de comunicação. Assim, esta educação proporcionou uma verdadeira invasão cultural (FREIRE, 2005), onde os interesses apropriados pelos educandos camponeses não eram compatíveis com suas necessidades.

Esta predileção pelo urbano, por parte das pedagogias e currículos escolares, materializou uma verdadeira oposição entre cidade e campo, onde a cidade é apresentada como lugar privilegiado, como único pólo cultural e artístico, como espaço superior por excelência, tendo uma dinâmica independente do campo, enquanto o rural é visto como naturalmente e hierarquicamente inferior e dependente da cidade. Esta oposição cidade/campo é fomentada tanto por livros didáticos, que não só nos textos, mas também nas fotografias e figuras desprivilegiam o espaço rural e sua população, como veremos posteriormente, quanto nas falas dos profissionais da educação ${ }^{3}$.

Se todos estes argumentos apresentados não forem suficientes para estruturar uma crítica contundente a este paradigma hegemônico, imagine ir para escola e lá aprender que o trabalho de seus pais é inferior e menos importante, que você deve estudar para ser alguém na vida, pois seus pais, parentes e amigos, não são ninguém na vida, pois vivem e trabalham no campo e isso não seria vida, imagine perceber que as representações do seu povo são o Jeca Tatu, o Nerso da Capitinga e o Chico Bento, e que os personagens das novelas brasileiras que vivem no campo, quando não são importantes fazendeiros, são verdadeiros "bocós", que só vestem roupas rasgadas e falam errado, e ainda por cima isso é transmitido em tom de comédia. Uma criança que crescesse aprendendo isso na escola e vendo isso na mídia iria sentir orgulho de ser do campo, iria querer lutar pela melhoria deste campo? Acreditamos que não.

Maria Helena S. Patto ao refletir sobre o poder do mito em torno do personagem de Monteiro Lobato, o Jeca Tatu, considerou que

No caso específico do discurso educacional, esta representação social do homem do campo transparece não só na crença generalizada e duradoura na indiferença ou aversão das populações rurais pela escola como também na crença dominante, durante um longo período, de que a verminose seria a principal causa do fracasso escolar das classes populares. (PATTO, 1990, p. 76) 
Os povos do campo organizados em movimentos sociais, principalmente no Movimento dos Trabalhadores Rurais Sem Terra (MST), ao tomarem consciência do descaso para com as escolas rurais e do preconceito para com o campesinato, principalmente os Sem Terra, constantemente criminalizados pela mídia e pelas instituições escolares, conscientizaram-se de que realmente não dava para lutar pelo campo e pela terra sendo educado em uma escola que silenciasse a problemática rural e depreciasse a vida rural, suas culturas, realidades e identidades múltiplas e diversas.

Neste ponto a luta não era mais restrita ao acesso à terra, sendo ampliada à luta pela dignidade e pelo reconhecimento da cidadania dos povos rurais, de suas responsabilidades como sujeitos históricos e de direitos. A luta também era pela construção e materialização de uma educação do campo, oposta ao paradigma da educação rural.

Caldart explicita bem a oposição entre o paradigma da educação rural e a educação do campo:

A Educação do Campo se constitui a partir de uma contradição que é a própria contradição de classe no campo: existe uma incompatibilidade de origem entre a agricultura capitalista e a Educação do Campo, exatamente porque a primeira sobrevive da exclusão e morte dos camponeses, que são os sujeitos principais da segunda. Em nosso debate isso tem sido referido como a principal oposição com a educação rural ou para o meio rural, que historicamente tem sido o nome dado às iniciativas do Estado de pensar a educação da população trabalhadora do campo, de modo a escamotear esta contradição e fazê-la de objeto e instrumento executor de políticas e modelos de agricultura pensados em outros lugares, e para atender a outros interesses que não os seus como grupo social, classe e pessoas. (CALDART, 2005, p.19)

Portanto, enquanto a educação rural estaria comprometida com interesses ruralistas de manutenção da exclusão e desigualdade fundiária, transmitindo um ensino adestratório, domesticador e desvalorizador do campo e de seus povos, a educação do campo seria uma construção dos próprios povos do campo de uma educação voltada para a valorização do campo e de sua gente, levando em conta as necessidades e especificidades das realidades rurais, com uma pedagogia que acredita no potencial econômico e cultural do campo, e na força política de suas populações organizadas em movimentos sociais rurais.

Enquanto a educação rural seria simplesmente transposta do espaço urbano e depositada para o dia-a-dia escolar rural, a educação do campo deve ser construída, discutida, debatida e reivindicada pela população rural e pelos 


\section{REVISTA TAMOIOS}

movimentos sociais, que articulados com o aparelho institucional escolar, fariam pressão à materialização de políticas públicas para a educação do campo que realmente fizessem parte da realidade das escolas rurais. Entretanto esta reivindicação legítima por políticas públicas e pelo tratamento público da educação no meio rural, direito dos povos do campo, por parte da articulação por uma educação do campo se opõe aos verdadeiros interesses do aparelho estatal a serviço do capitalismo, que já construiu e materializou a educação rural como o paradigma a ser seguido.

Em trabalho anterior (CORDEIRO, 2009) esquematizamos, a partir de dados da Secretária de Educação Continuada, Alfabetização e Diversidade (SECAD), a evolução das conquistas a nível governamental da proposta de uma educação do campo, que começaram com a criação em 1998 da "Articulação Nacional por uma Educação do Campo", entidade supra-organizacional ligada ao movimento de reivindicação nacional pela escolarização dos povos do campo, que resultou em duas "Conferências Nacionais por uma Educação Básica do Campo" em 1998 e 2004. Em 2003 houve a instituição pelo Conselho Nacional de Educação (CNE) do Grupo Permanente de Trabalho de Educação do Campo (GPT), além da promulgação das Diretrizes Operacionais para a Educação Básica nas Escolas do Campo (2002). Em 2004 o Ministério da Educação criou a SECAD vinculada à Coordenação Geral de Educação do Campo.

Portanto, existem no que se refere aos níveis legislativos normatizações em relação à especificidade da educação em escolas rurais a começar pela LDB, Lei 9.494/96:

Art. 28. Na oferta de educação básica para a população rural, os sistemas de ensino promoverão as adaptações necessárias à sua adequação às peculiaridades da vida rural e de cada região, especialmente:

I - conteúdos curriculares e metodologias apropriadas às reais necessidades e interesses dos alunos da zona rural;

II - organização escolar própria, incluindo adequação do calendário escolar às fases do ciclo agrícola e às condições climáticas;

III - adequação à natureza do trabalho na zona rural.

Mas somente na Resolução e no Parecer das Diretrizes Operacionais para a Educação Básica nas Escolas do Campo existe o uso da categoria escola do campo de acordo com as reflexões dos movimentos sociais.

Art. $2^{\circ}$

Parágrafo único. A identidade da escola do campo é definida pela sua vinculação às questões inerentes à sua realidade, ancorando-se na temporalidade e saberes próprios dos 
estudantes, na memória coletiva que sinaliza futuros, na rede de ciência e tecnologia disponível na sociedade e nos movimentos sociais em defesa de projetos que associem as soluções exigidas por essas questões à qualidade social da vida coletiva no país. (RESOLUÇÃO CNE/CEB, 2002).

Apesar da luta pela educação do campo ter ganhado terreno na legislação e políticas públicas, acreditamos e percebemos que estas conquistas se dão em âmbito extra-escolar, pois o cotidiano da escola, dos currículos (PCN's), dos livros didáticos e da formação de professores, permanece, infelizmente, quase que inalterados. Isso vem afirmar que nas escolas rurais brasileiras o paradigma seguido ainda é, majoritariamente, o da educação rural. Mesmo nas escolas de assentamentos e acampamentos do MST a disputa ideológica ainda é desigual para a educação do campo.

Por isso, partimos do pressuposto de que a educação do campo não é um paradigma contra-hegemônico, pois não está materializada no chão da escola, e sim que a luta que se faz é pela construção coletiva deste novo e possível paradigma que só poderá ser considerado um paradigma contra-hegemônico se estruturado a partir e junto dos povos do campo. Justamente por que a apropriação da categoria de educação do campo pelo Estado e governos brasileiro deve ser vista mais com cautela do que como sinônimo de vitória ${ }^{4}$.

\section{Educação Rural e Modernidade}

Ao aprofundarmos nossa reflexão acerca do paradigma da educação rural percebemos a relação estreita entre este paradigma e o paradigma moderno, isto por que o ideário moderno apresentado a partir da racionalidade, cientificidade e positividade, usou destes pressupostos para colonizar, escravizar e trucidar povos em nome da civilidade. Importante admitirmos que "Não há como querer ficar só com o lado bom da modernidade, olvidando-se do seu contrário historicamente necessário, a colonialidade" (PORTO-GONÇALVES, 2003, p. 5). Portanto, existe na modernidade uma hierarquização da humanidade (dawirnismo social), entre povos evoluídos e povos primitivos, onde os primeiros teriam a missão de civilizar os últimos. Este aspecto do paradigma moderno, que apesar de ter sido legitimado há séculos ainda persiste, está de acordo com a natureza da educação rural, onde os povos do campo são vistos como inferiores e atrasados e, por isso, deveriam ver o mundo a partir da civilidade urbana, através também da escola.

Em relação ao paradigma moderno Santos acredita que este

paradigma se constitui contra o senso comum e recusa as orientações para a vida prática que dele decorrem; um 
paradigma cuja forma de conhecimento procede pela transformação da relação eu/tu em relação sujeito/objeto [...]; um paradigma que pressupõe uma única forma de conhecimento válido, o conhecimento científico, cuja validade reside na objetividade de que decorre a separação entre teoria e prática, entre ciência e ética; um paradigma que tende a reduzir o universo dos observáveis ao universo dos quantificáveis [...]; um paradigma que avança pela especialização e profissionalização do conhecimento, com o que gera uma nova simbiose entre saber e poder, onde não cabem os leigos, que assim se vêem expropriados de competências cognitivas e desarmados dos poderes que ela conferem. (SANTOS, 2000, p. 34)

O autor enumera algumas características do pensamento moderno que, como já dito, vão de encontro aos ideais de uma educação rural. Assim, o ensino para as populações rurais teria objetivos bem definidos como a domesticação, alienação, reprodução de ideologias ruralistas e a inferiorização, e em termos curriculares esta educação seria de baixa qualidade, inferior quando comparada à urbana, já que "Em nossa história domina a imagem de que a escola no campo tem que ser apenas a escolinha rural das primeiras letras. A escolinha cai não cai, onde uma professora que quase não sabe ler ensina alguém a não saber quase ler" (ARROYO, CALDART, MOLINA, 2004, p. 71).

Mignolo considera em relação à modernidade que:

O imaginário do mundo moderno/colonial surgiu da complexa articulação de forças, de vozes escutadas ou apagadas, de memórias compactas ou fraturadas, de histórias contadas de um só lado, que suprimiram outras memórias, e de histórias que se contaram e se contam levando-se em conta a duplicidade de consciência que a consciência colonial gera. (MIGNOLO, 2005, p. 80)

Assim, as populações campesinas tiveram suas vozes silenciadas, suas memórias fraturadas e suprimidas, e além do dito, por conta da invasão cultural (FREIRE, 2005) passaram a ver o mundo através do olhar opressor, representados pelos ideais eurocêntricos e coloniais, por isso mesmo, modernos.

A própria ideia de escola que temos está estreitamente ligada à modernidade, pois esta escola é uma instituição moderna que transmite, portanto, a ideologia moderna, como bem provoca Silva:

A educação escolarizada e pública sintetiza, de certa forma, as idéias e os ideais da modernidade e do iluminismo. Ela 
corporifica as idéias de progresso constante através da razão e da ciência [...], de universalismo, [...] de autonomia e liberdade [...]. Ela não apenas resume esses princípios, propósitos e impulsos, ela é a instituição carregada de transmiti-los, de torná-los generalizados, de fazer com que se tornem parte do senso comum e da sensibilidade popular. A escola pública se confunde, assim, com o próprio projeto da modernidade. É a instituição moderna por excelência. (SILVA, 1996, p. 251)

Já Porto-Gonçalves considera a colonialidade, ou seja, a força do pensamento colonial que se materializa através do conhecimento, do poder e do ser, correlacionada à modernidade.

A colonialidade do Saber nos revela ainda, que, para além do legado de desigualdade e injustiça sociais profundos do colonialismo e do imperialismo, já assinalados pela teoria de dependência e outras, há um legado epistemológico do eurocentrismo que nos impede de compreender o mundo a partir do próprio mundo em que vivemos e das epistemes que Ihe são próprias. (PORTO-GONÇALVES, 2005, p. 10)

A Modernidade se constitui no mesmo movimento que constitui a colonialidade. Assim, é preciso romper com o evolucionismo eurocêntrico que vê cada lugar do mundo como se fora um determinado estágio da evolução européia, o que só é possível a partir de uma perspectiva teórica que toma o tempo como algo linear (o europeu) e ignora o espaço, enfim, uma perspectiva teórica que pensa a sucessão de eventos numa linha temporal unidirecional e ignora a simultaneidade constitutiva da história (espaço-tempo). Pensar com o espaço implica admitir múltiplas temporalidades convivendo simultaneamente. (PORTO-GONÇALVES, 2003, p. 4)

Lander (2005, p. 34), concluiu que neste processo de hegemonização dos saberes coloniais "As outras formas de organização da sociedade, as outras formas de conhecimento, são transformadas não só em diferentes, mas em carentes, arcaicas, primitivas, tradicionais, pré-modernas", os não europeus são somente os outros, e o lócus de enunciação dos discursos, das práticas, teorias e das ideias, é sempre europeu ou civilizado, por que não, urbanocentrado.

Este pensamento moderno iniciado a partir do século XV (DUSSEL, 2005), que possibilitou a emergência do sistema mundo moderno colonial, começa a ser posto em dúvida a partir dos movimentos de descolonização, que questionaram as diversas formas de dominação propiciadas e legitimadas pelo colonialismo e pelo 


\section{REVISTA TAMOIOS}

pensamento moderno. Através destes questionamentos começam a ganhar força pensamentos subalternos, além de alternativas à superação do pensamento moderno colonial.

Em nossa perspectiva a educação do campo configura-se como uma construção alternativa a este pensamento materializado a partir da educação rural. Ou seja, na educação do campo as qualidades que diferenciam os povos, as raças e etnias seriam vistas não mais a partir do pressuposto das diferenças negadas, e sim como qualidades propriamente ditas, até mesmo como complementaridades.

Portanto, entendemos que a cultura e saberes campesinos foram transformados em diferentes, arcaicos, primitivos, tradicionais e inferiores por conta desta colonialidade oculta ao pensamento moderno, e legitimados pelo paradigma da educação rural. Porém, com a emergência de formas de resistência ao padrão moderno colonial de mundo surgem no Brasil movimentos (de contestação) social camponeses, como o já citado Movimento dos Trabalhadores Rurais Sem Terra (MST), incentivador e interlocutor da superação do paradigma da educação rural através da construção e emergência do paradigma da educação do campo.

\section{PENSAMENTO MODERNO, ENSINO DE GEOGRAFIA E EDUCAÇÃO RURAL}

Podemos considerar que desde os seus primórdios o ensino de geografia serviu à reprodução dos ideais dominantes, principalmente a nacionalidade e sentimento cívico de pertencimento ao território que foram úteis, como muito bem apresentou Lacoste, à guerra.

A função ideológica essencial do discurso da geografia escolar e universitária foi sobretudo a de mascarar por procedimentos que não são evidentes, a utilidade prática da análise do espaço, sobretudo para a condução da guerra, como ainda para a organização do Estado e prática do poder. É sobretudo quando ele parece "inútil" que o discurso geográfico exerce a função mistificadora mais eficaz, pois a crítica de seus objetivos "neutros" e "inocentes" parece supérflua. A sutileza foi a de ter passado um saber estratégico militar e político como se fosse um discurso pedagógico ou científico perfeitamente inofensivo. Nós veremos que as conseqüências desta mistificação são graves. (LACOSTE, 2005, p. 25)

Ponderamos a necessidade de se ter em mente o contexto histórico e político no qual estas críticas foram elaboradas por Lacoste, principalmente o fato desta se direcionar à potencialidade estratégica da geografia para a guerra. Porém, ponderações feitas, acreditamos que a crítica direcionada ao Estado e à geografia 
dos professores é pertinente à confrontação aqui proposta. Ao mascarar a potencialidade prática da análise do espaço, a geografia igualmente mascara as relações que ocorrem neste mesmo espaço, e por servir a prática do poder e a organização do Estado serve igualmente aos interesses deste. Assim podemos considerar que

Foi, indiscutivelmente, sua presença significativa nas escolas primárias e secundárias da Europa do século XIX que a institucionalizou como ciência, dado o caráter nacionalista de sua proposta pedagógica, em franca sintonia com os interesses políticos e econômicos dos vários Estados-nações. Em seu interior, havia premência de se situar cada cidadão como patriota, e o ensino de Geografia contribuiu decisivamente neste sentido, privilegiando a descrição do seu quadro natural (VLACH apud NABARRO; TSUKAMOTO, 2009, p. 6)

A geografia escolar, deste modo, foi utilizada como instrumento de dominação a partir da propagação de interesses não-coletivos, já que privados, através do ideário moderno, nas instituições escolares de todo o mundo, inclusive do Brasil.

No nosso país o ensino foi e ainda é afetado pelo colonialismo, iniciando-se com os jesuítas com aspirações de civilização e desmembramento das estruturas culturais, políticas e econômicas indígenas, que juntamente com a migração européia contribuíram para ocupação do território por não-indígenas, para o "embranquecimento" da população e para a propagação da dita história oficial (moderna). Deste então as culturas indígenas e afro-descendentes foram silenciadas e ocultadas. Assim sendo, ocorreu a emergência da valorização e da dominação das oligarquias rurais, através do coronelismo. Estas oligarquias, principalmente as relacionadas com o cultivo do café, acabaram posteriormente constituindo os primeiros centros urbano-industriais brasileiros e, consequentemente, os primeiros industriais brasileiros, muitos descendentes destes guardam até hoje suas relações com o meio rural e com as atividades agrárias.

Como vimos a inferiorização e "domesticação" dos povos do campo é de interesse do Estado e governos brasileiros, já que ambos agem de acordo com uma elite econômica agrário-industrial. As políticas públicas brasileiras serviriam neste sentido tanto para a manutenção das relações desiguais no campo, como para a contenção do êxodo rural e, principalmente, para a perpetuação da atual estrutura fundiária. Da mesma forma as instituições escolares pertencentes ao Estado reproduzem os mesmos interesses mascarando a potencialidade da geografia na escola e incorporando discursos ideológicos que não estão de acordo com os interesses dos povos do campo.

Assim sendo, o ensino de geografia tradicional foi oportuno ao paradigma da educação rural, já que sempre esteve articulado à ciência moderna e aos interesses dos Estados Modernos. Ao refletir sobre a relação entre o moderno e o urbano 


\section{REVISTA TAMOIOS}

Gomes (2007, p. 62) considera que "trata-se da mesma associação que se encontra nos discursos de diversos geógrafos, para quem a tradição e o antigo estão ligados de uma forma intrínseca ao mundo rural e o fenômeno urbano é o evento maior da modernidade", ou seja, entendemos que a geografia moderna tem um lócus de enunciação urbano colonial.

A escola ao ter o urbano como parâmetro e o rural como adaptação ou adequação ao parâmetro negligencia o seguinte fato:

O aluno do meio rural quando chega à escola já traz de casa toda uma bagagem de conhecimento valorativo criado a partir das relações anteriormente estabelecidas, mas no atual processo educativo a escola é, em contrapartida, a negação do meio rural, pois realça as diferenças culturais deste aluno e, por isso, ela o expurga, uma vez que não o reconhece enquanto sujeito desta relação. (MENDES, MESQUITA, 2009, p. 491)

Acrescentamos que a geografia não reconhece estes alunos como sujeitos da espacialidade ou da territorialidade rural, desse modo não reconhece os saberes espaciais, políticos e culturais destes alunos como saberes geográficos, o que seria extremamente enriquecedor no processo de ensino-aprendizagem de geografia.

Em relação à estrutura curricular da geografia, acreditamos ser importante ressaltar a dicotomia existente entre homem e natureza (física-humana), característica do pensamento moderno, que ao retirar o homem da natureza tratando-a somente como recurso a ser explorado, ignora uma herança cultural de indígenas, quilombolas e/ou camponeses de pertencimento a natureza, que é vista por estes como fonte de vida. Assim, a natureza é desumanizada e o homem desnaturizado (MOREIRA, 2008), exatamente o oposto da relação entre os povos do campo junto à natureza, o que se materializa no discurso da geografia escolar onde o trabalho do campesinato é subalternizado, visto como atrasado, oposto ao moderno, como se fosse possível a modernidade desprovida das atividades agrícolas.

O homem e a natureza não formariam neste contexto uma unidade, ao contrário o objetivo do homem seria vencer a natureza, coisificá-la. Portanto, a geografia, segundo Moreira (2008), compartimentada em uma estrutura naturezahomem-economia (N-H-E), vê o homem como atópico, deslocado da natureza e da sociedade, o que seria a fonte do problema epistemológico da geografia. Entendemos que esta fragmentação no ensino de geografia também contribui para uma geografia que mascara a realidade e que reproduz os ideais modernos, contribuindo para o não entendimento do todo através da valorização excessiva das partes.

A negligencia em relação ao espaço rural ganhou terreno em muitos conceitos e categorias geográficas como espaço, região e território. Através destes 


\section{REVISTA TAMOIOS}

conceitos o urbano ganhou conotações de desenvolvimento enquanto o rural foi apresentado como sinônimo de atraso. Até mesmo o conceito de lugar demonstrou por muito tempo um distanciamento ao cotidiano, ao dia-a-dia dos seres humanos, ao espaço vivido e produzido por estes. O distanciamento se tornou mais concreto no meio rural, já que muitos conceitos assumiram ideologicamente no ensino de geografia um caráter urbano.

Acreditamos que uma forma de romper este distanciamento poderia ser os conceitos de lugar e paisagem, principalmente a partir da visão da geografia humanística onde o primeiro conceito está carregado da noção de espaço vivido. Dessa forma, o lugar e a paisagem dos alunos deveriam ser espaços privilegiados no ensino de geografia. Partindo do entendimento da paisagem cotidiana e da idéia de lugar como produto das relações histórico-sociais concretas e subjetivas, a geografia daria destaque ao espaço rural trabalhando-o profundamente para posteriormente sair do local para o regional e global. Concordamos que não é possível entender nossa realidade sem entender nosso mundo, porém acreditamos ser impossível entender nosso mundo sem entender nossa própria realidade.

Porém, não só o lugar e a paisagem, como todos os conceitos e categorias geográficas, abrangem e podem valorizar o meio rural, o que não ocorre é um consciência, por parte de currículos e docentes, da realidade, consequentemente, dos espaços, aos quais estão inseridos os discentes, onde estes conceitos e categorias serviriam como ferramentas para a compreensão desta mesma realidade. É para isso que servem os conceitos geográficos, são ferramentas para o entendimento das relações, produções e saberes espaciais globais e locais, o que acontece é uma ocultação do local quando este é o meio rural.

\section{Os livros didáticos de geografia: ideologia da educação rural?}

Como já dito, a maioria dos livros didáticos não estão de acordo com a diversidade nacional, até mesmo pelo fato de os livros adotados terem o mesmo conteúdo para todo o Brasil. Evidentemente em um único livro não seria possível contemplar todas as realidades e culturas de todos os povos que formam a nação brasileira. O que ocorre, portanto, é uma generalização onde a realidade que prevalece é a dos grandes centros urbanos brasileiros, principalmente o Centro-Sul, onde estão grande parte das editoras e dos autores dos livros didáticos. Porém, este fato por si só não justifica certas visões apresentadas, como: a visão da zona urbana como progresso e da zona rural como atraso; a simples correlação entre subdesenvolvimento, agricultura e trabalho tradicionais; a absurda correlação entre o problema mundial da fome e a agricultura e trabalho tradicionais; a suposição de que os alunos que irão utilizar estes livros conhecem a vida urbana e as grandes cidades; a visão de que as agroindústrias trazem desenvolvimento e progresso para o campo e sua população; entre outros equívocos. 


\section{REVISTA TAMOIOS}

Vejamos um exemplo de como um livro didático de geografia generalizou toda a população nacional, não levando em conta as diversidades existentes:

No lugar e na casa onde moramos, há vários objetos que estabeleceram e estabelecem várias ligações com o espaço geográfico. Por exemplo, logo que acordamos, uma das nossas primeiras ações é acender a lâmpada. Esse simples ato pressupõe a existência de usinas de geração de energia elétrica, redes de transmissão, fábricas que produziriam os equipamentos, empresas de fornecimento de energia, etc. ( SENE, MOREIRA, 2003, p. 188)

A realidade de nosso país não permite este tipo de afirmação, principalmente nas áreas rurais onde, infelizmente, não chegaram vários tipos de infraestruturas, entre elas a energia elétrica, ou seja, ao tentar igualar todos os brasileiros, que pela manhã fariam a mesma ação de acender a lâmpada elétrica, o autor exclui e inferioriza aqueles que não se adequam a sua generalização. Ao observarmos como os capítulos de outro livro didático (VESENTINI, VLACH, 2007) se dividem e subdividem, e algumas de suas figuras, vimos que:

- Espaço Urbano: 1 - A divisão do trabalho entre campo e cidade; 2 Urbanização e industrialização; 3 - O sítio urbano, a situação e a função das cidades; 4- O centro e a expansão da cidade; 5 - A rede urbana; 6- As megalópoles; 7 - A urbanização do mundo; 8 - O crescimento urbano no Brasil.

- Espaço Rural: 1 - A indústria moderna e as transformações no setor primário; 2 - Atividade rural e fome no Sul; 3 - A agropecuária nos países subdesenvolvidos; 4 - A agropecuária nos países desenvolvidos; 5 - A agropecuária nos demais países; 6 - A atividade rural no Brasil. 
Figura 1 e Figura 2

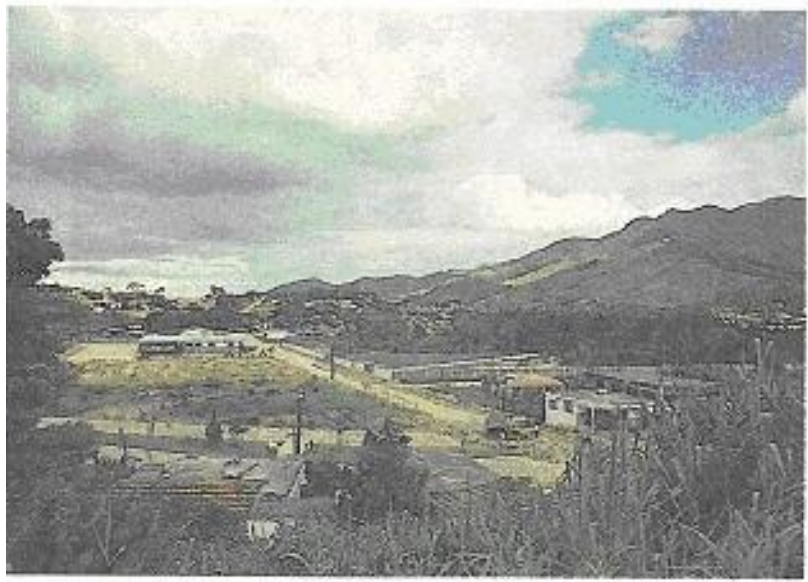

Miracatu

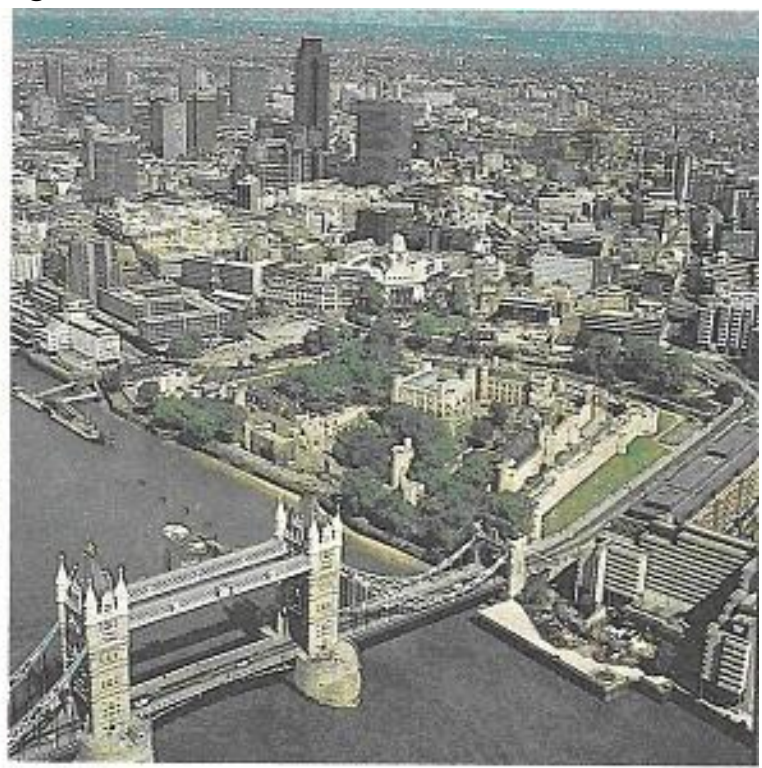

Londres

As fotos mostram duas cidades: Miracatu (estado de Sāo Paulo) e Londres (Inglaterra). Apesar das enormes diferenças que existem entre ambas, as atividades que nelas se desenvolvem sāo tipicamente urbanas.

Uma cidade vive dos setores secundário (indústrias) e terciário (comércio, bancos, serviços, etc.); o meio rural, por sua vez, dedica. se principalmente às atividades primárias (agricultura, pecuária e extrativismo).

Fonte: VESENTINI, J. W; VLACH, S. Geografia Crítica. 2ํvol. 2ª Ed. São Paulo: Ática, 2007.

Apesar dos autores evidenciarem a complementaridade existente na relação entre cidade e campo, no capítulo sobre o espaço urbano são apresentadas as características e funções deste espaço. As figuras 1 e 2 ilustram o tópico 1 - $A$ divisão do trabalho entre campo e cidade, em todo o capítulo são mostradas figuras neste padrão: as grandes cidades do mundo, evidenciando suas estruturas sem considerar seus problemas.

Já no capítulo sobre o espaço rural os autores discutem o problema da fome e do subdesenvolvimento, como se estes estivessem restritos as suas relações com o espaço rural. O pior são as figuras inseridas nestes tópicos, onde a figura 3 está no tópico 2- Atividade rural e fome no sul, ilustrando crianças negras desnutridas do mundo subdesenvolvido, e a figura 4 está no tópico 3- $A$ agropecuária nos países subdesenvolvidos, ilustrando camponeses negros africanos trabalhando na agricultura tradicional, o que também é relacionado ao subdesenvolvimento.

Podemos considerar que a figura 3 não só inferioriza o espaço rural ao relacioná-lo com crianças extremamente desnutridas, como também inferioriza a população negra representada na foto. Além disso, os autores ao inserirem neste capítulo a problemática da fome ignoram toda a trama do capitalismo moderno colonial que tornou possível situações como as representadas na figura, que vão além dos problemas existentes no espaço rural. 


\section{REVISTA TAMOIOS}

Figura 3

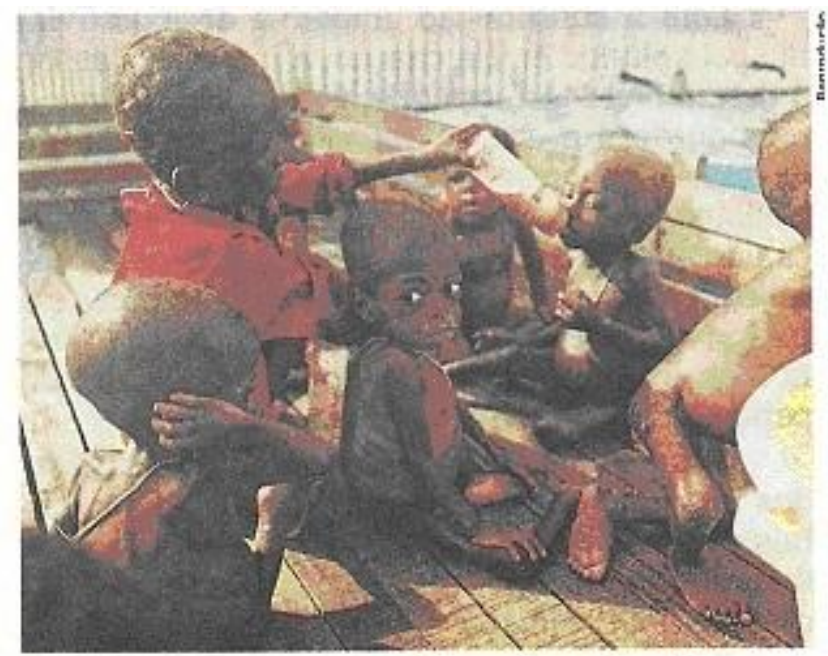

A fome, um dos mais graves problemas do mundo subdesenvolvido, atinge particularmente as crianças, muitas das quais morrem por inaniçāo.

Fonte: VESENTINI, J. W; VLACH, S. Geografia Crítica. $2^{\circ}$ vol. $2^{\text {a }}$ Ed. São Paulo: Ática, 2007.

Como podemos observar a figura 4 relaciona o subdesenvolvimento com a agricultura tradicional, desconsiderando a colonização, a colonialidade e o impacto negativo das agroindústrias voltadas ao comércio exterior para as populações camponesas.

Figura 4

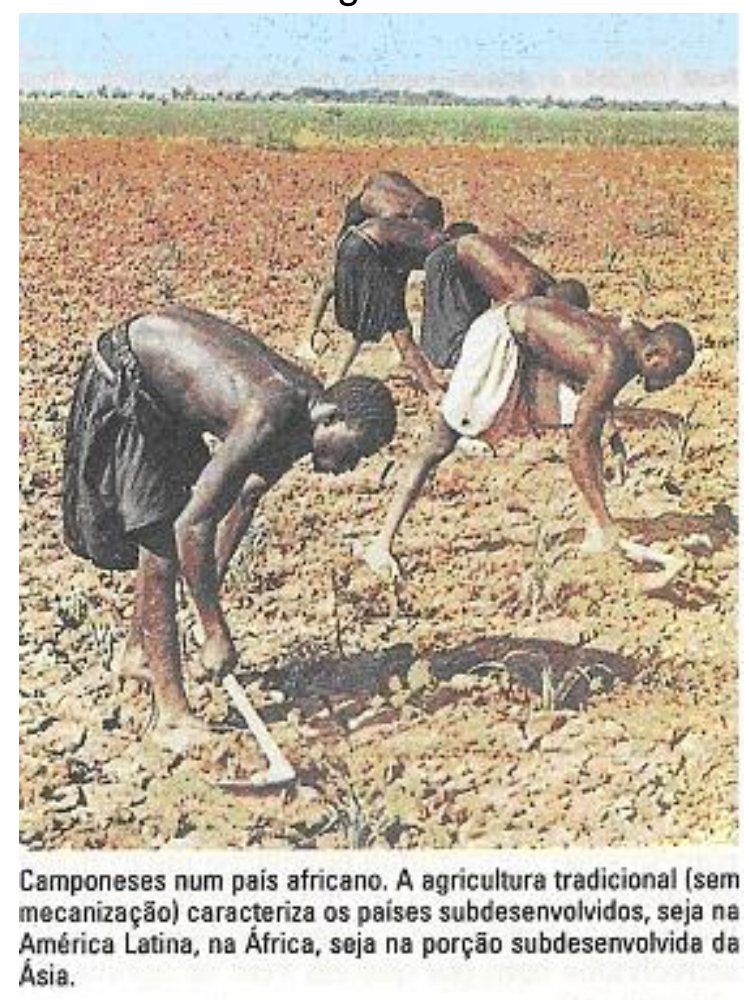

Fonte: VESENTINI, J. W; VLACH, S. Geografia Crítica. $2^{\circ}$ vol. $2^{\underline{a}}$ Ed.

São Paulo: Ática, 2007. 


\section{REVISTA TAMOIOS}

Também encontramos um exemplo, em livro didático da $3^{\text {a }}$ série ou $4^{\circ}$ ano, onde o urbano é viso como parâmetro e o rural como adaptação ou contrário ao urbano: "Pode ser que você não more em uma cidade, mas com certeza já visitou alguma ou viu cidades em fotos de jornais e revistas, na televisão ou no cinema" (VESENTINI; DIAS; PÉCORA, p. 10, 2008), "Campos cultivados, pastagens, sítios, montanhas. Certamente você já sabe que as paisagens do campo são bem diferentes das paisagens das cidades" (Ibid, p. 18, 2008).

Em outro livro didático de ensino médio, "as relações de trabalho no campo" são tratadas da seguinte forma:

Geralmente encontramos entre os trabalhadores rurais brasileiros baixos indicadores socioeconômicos, como elevada natalidade, elevado analfabetismo, pequena qualificação profissional e baixa remuneração. Além disso, eles sofrem com a falta de cumprimento da legislação trabalhista por parte de alguns patrões e o elevado número de acidentes com ferramentas, como facões. Quanto mais distantes das principais cidades e capitais, mais tensas são as relações sociais no campo. (ALMEIDA; RIGOLIN, 2003, p. 410)

Esta forma simplista, que não leva em consideração a historicidade, é utilizada para explicar o porquê dos indicadores socioeconômicos dos espaços rurais serem mais baixos. Os autores relacionam estes indicadores com a distância em relação às cidades, como se nas cidades estes tipos de problemas não existissem, inclusive o trabalho informal e irregular. Consideramos que o livro, neste trecho citado, praticamente leva o aluno a entender que esta relação de desigualdade entre campo e cidade é natural.

Em outro trecho do mesmo livro, ao tratarem da "tensão no campo", os autores criminalizam a luta pela terra ao simplificarem novamente as condições concretas e simbólicas da luta:

Os invasores do MST argumentam que estão tomando posse de terras improdutivas e o outro lado considera essa atitude um ato criminoso que fere o direito de propriedade. [...]

Os conflitos no campo e a participação do MST em invasões que nem sempre visam se apossar de terras improdutivas, como nas freqüentes tentativas de ocupação da fazenda dos filhos do presidente Fernando Henrique Cardoso, são um assunto polêmico na sociedade brasileira. Enquanto alguns líderes fazem do movimento uma "profissão", inocentes são sacrificados nessa luta desigual pelas terras no Brasil. (ALMEIDA; RIGOLIN, 2003, p. 412) 
Os autores deixam bem claro suas escolhas ideológicas ao optarem pela categoria de "invasão" ao invés da de "ocupação", já que o primeiro termo refere-se a um ato ilegal e o segundo ganha uma conotação política de luta por direitos negados, assim como pelo uso da expressão "apossar". Também usam da ironia ao criticarem os líderes que, em suas visões, tratam a luta como uma "profissão" como se este fato carregasse em si estigmas negativos. Para os alunos que vivem no campo estas posições ideológicas negam a necessidade de organização de movimentos sociais ao mesmo tempo em que incentivam a passividade, já para os alunos que vivem em acampamentos e assentamentos do MST as consequências são bem mais profundas já que estão possivelmente integrados na luta. Esta forma de tratar a questão pode levar aos alunos do MST até mesmo os sentimentos de vergonha e humilhação.

Nabarro e Tsukamoto (2009, p. 23) ao pesquisarem como a questão agrária é tratada nos livros didáticos de Londrina perceberam como a mesma é tratada de forma "antediluviana" e em relação à reforma agrária concluíram que "os livros didáticos não deixam claro que uma reforma agrária não é uma simples distribuição de terras". Portanto, consideraram que "Muitos foram os problemas identificados, no entanto cabe ao professor o trabalho de esclarecer os equívocos e dar as definições adequadas aos termos empregados de forma incorreta nos textos dos livros didáticos" (ibid, p. 24). A questão problematizada neste trabalho é até que ponto os professores têm condições de esclarecer tais equívocos e até que ponto é de interesse do Estado e do governo brasileiro esta postura. Fazemos esta ponderação por considerarmos que os livros didáticos transmitem uma ideologia conivente com os interesses do Estado vinculada ao capitalismo moderno colonial. Nabarro e Tsukamoto consideram que:

Ocorre que a ideologia na escola não se manifesta apenas no formato das edificações, ou nas atitudes de educadores e educandos. Os materiais de apoio as aulas, normalmente elaborados por órgãos do Estado ou por editoras, homogeneízam conteúdos, não valorizando assim realidades locais, impondo a visão dominante. Dentre estes materiais de apoio destacamos o livro didático, material mais utilizado nas escolas brasileiras" (ibid, p. 13)

Estes exemplos foram aqui expostos somente para elucidar a relação entre educação rural e o ensino de geografia, presente também nos livros didáticos. Além desses exemplos existem muitos outros talvez mais contundentes e perversos, principalmente em coleções mais antigas. Nosso objetivo aqui não é o de analisar coleções de livros didáticos de geografia sistematizando seus equívocos, baseados ou não na educação rural, nosso objetivo neste tópico foi o de exemplificar os questionamentos apresentados por nós. Porém consideramos necessária a análise 


\section{REVISTA TAMOIOS}

e sistematização de algumas coleções de geografia em outro momento, como continuidade desta pesquisa.

\section{Considerações Finais}

\section{Uma geografia do campo é possível?}

"os diferentes movimentos sociais resignificam o espaço e, assim, com novos signos grafam a terra, geografam, reinventando a sociedade"

Carlos Walter Porto - Gonçalves

Através desta pesquisa foi possível perceber a face moderna, colonial e eurocêntrica do pensamento geográfico, principalmente, mas não somente, do ensino de geografia pautado no pensamento geográfico tradicional. Face esta que contribuiu para a atual configuração do mundo, para atrocidades cometidas em nome da Modernidade, entre elas a subalternização da vida e dos povos do campo, através de um ensino de geografia refém do paradigma da educação rural. Sabemos que muitos outros grupos sociais também foram e ainda são postos à margem com o auxílio da geografia: indígenas, negros, quilombolas, mulheres, sem-tetos, etc. Entretanto, vemos também uma nova possibilidade contra-hegemônica capaz de geografar (PORTO-GONÇALVES, 2003) de outra forma o mundo.

Para tanto existe a necessidade de uma geograficidade social (PORTOGONÇALVES, 2003) que leve em conta todas as subalternidades anteriormente negadas, inferiorizadas e silenciadas, uma geograficidade onde os subalternos geografem o mundo, construindo uma nova práxis, um novo devir. Esta nova grafia do espaço por parte dos movimentos sociais, trava uma luta entre estes e os grupos dominantes, já que

El espacio no es simplemete el dominio del estado que lo administra, ordena y controla (representaciones del espacio), sino la siempre dinâmica y fluida interacción entre lo local y lo global, lo individual y lo colectivo, lo privado y lo público, y entre resistencia y dominacion. En el espacio se brinda entoces también el potencial de desafiar y subvertir el poder dominante, y por eso forma parte esencial de uma política de resistencia como articulada, por ejemplo, por movimientos sociales. (OSLANDER, 2002, p. 10) 
Concordamos com o entendimento de Oslender em relação à configuração de uma "Espacialidad de Resistencia" onde as contradições do espaço capitalista moderno colonial produzem espaços de resistências, das diferenças e das subalternidades que resistem contra-hegemônicamente "la colonización de los espacios concretos" (ibid, 2002, p. 4).

Consideramos que os movimentos sociais rurais, articulados com as populações campesinas em geral e os centros de pesquisas, que lutam por uma educação do campo estão em um processo de construção de uma espacialidade de resistência à educação rural $\mathrm{e}$, consequentemente, ao pensamento moderno colonial. Porém, os territórios disputados - as escolas rurais, ainda estão longe de serem consideradas como espaços de resistência ${ }^{5}$, ao contrário ainda são espaços de subordinação à lógica do Estado brasileiro, ou seja, à educação rural.

Acreditamos que a geografia não pode, através da academia ou da escola, negar, omitir ou negligenciar a geograficidade dos movimentos sociais rurais que, juntamente com os povos do campo em geral, fazem força para a materialização de uma educação do campo que prescinde de uma geografia escolar comprometida com o espaço de lutas campesino. Porém, vimos ao longo deste artigo que a geografia além de utilizar suas ferramentas de auxílio à inteligibilidade do mundo seus conceitos e categorias, de forma a privilegiar o urbano, também materializa pressupostos da educação rural em seus livros didáticos, que seguem os Parâmetros Curriculares Nacionais (PCN's).

Outra questão pertinente ao tema evidenciado no artigo é a estreita relação entre o pensamento moderno colonial e o paradigma da educação rural, onde este paradigma seria "discípulo" da Modernidade no Brasil. Também não podemos, nem é nossa intenção, negar a estreita relação entre o pensamento moderno colonial e a geografia moderna, que travou uma batalha sem precedentes para conseguir o estatuto moderno de ciência, servindo aos interesses dos grupos dominantes indo do determinismo geográfico à colonialidade. $O$ que fizemos neste trabalho foi articular o pensamento moderno colonial à educação rural e ambos ao ensino de geografia, investigando suas relações e suas consequências, visando, de acordo com nossas modestas possibilidades, fomentar a transformação desta realidade em uma outra realidade.

Portanto, nossa intenção nesta pesquisa, além de apresentar a relação entre o ensino de geografia e a educação rural, foi a de estimular a reflexão sobre a contribuição da geografia escolar na construção destes espaços de resistência no chão das escolas rurais, questionando: uma geografia do campo é possível? Acreditamos que sim. 


\section{REVISTA TAMOIOS}

\section{Notas}

1- Professora de geografia das redes municipal e estadual de educação, atuando no $2^{\circ}$ segmento do ensino fundamental, modalidade regular, no município de Rio Bonito, inclusive em escola rural, a Escola Municipalizada Professor Santos Loureiro.

2- Consideramos que "São trabalhadores. Seus significados jamais são confundidos com outros personagens do campo: fazendeiros, latifundiários, seringalistas, senhores de engenho, coronéis, estancieiros... As palavras exprimem as diferentes classes sociais" (ARROYO, CALDART, MOLINA, 2004, p. 26).

3- Tanto em minha experiência docente quanto em meus estágios em escolas rurais, presenciei falas depreciativas em relação ao espaço rural por professores e direção. Em uma das ocasiões escutei que "eles têm que estudar para sair deste buraco".

4- Existem programas do governo intitulados como sendo de educação do campo, vinculados a SECAD, porém estes mesmos programas impõem de cima para baixo a educação do campo, sem uma reflexão e construção coletiva entre Governo Federal (MEC), escolas, movimentos sociais e comunidades rurais, ou seja, existe a princípio uma apropriação da categoria e não a construção de um paradigma, o Programa Escola Ativa exemplifica bem, ao nosso entender, esta situação.

5- Exceto algumas experiências de escolas do MST, na luta pelo processo de construção do paradigma da educação do campo e de uma "espacialidad de resistencia" (OSLANDER, 2002), que estão conseguindo aos poucos incorporar estes pressupostos e enfrentar a luta desigual contra o Estado e a mídia.

\section{Referências Bibliográficas}

ALMEIDA, L. M. A; RIGOLIN, T. B. Geografia. Série Novo Ensino Médio. São Paulo: Ática, 2003.

ARROYO, M. G; CALDART, R. S. \& MOLINA, M. C. (orgs). Por uma Educação do Campo. Petrópolis, RJ: Vozes, 2004.

BRASIL/MEC. Lei 9.394/96. Lei de Diretrizes e Bases da Educação brasileira. Disponível em <www.planalto.gov.br>. Acesso em 08 mar. de 2010. 


\section{REVISTA TAMOIOS}

BRASIL/MEC. Diretrizes Operacionais para a Educação Básica nas Escolas do Campo. Resolução CNE/MEC 1/2002. Diário Oficial da União, Brasília. Seção 1, p.32, abr./2002.

CALDART, R. S. Pedagogia do Movimento Sem Terra. $3^{\text {a }}$ Ed. São Paulo: Expressão Popular, 2004.

CALDART, R. S. Elementos para a construção de um projeto político e pedagógico da Educação do Campo. In: MOLINA, M. C; JESUS, S. M. A. Por uma educação do campo. Vol. 5. Brasília, DF: Articulação Nacional "Por Uma Educação do Campo", 2005.

CORDEIRO, T. G. B. F. Educação do Campo: a conflitualidade e a contraditoriedade de uma educação transformadora legitimada pelo Estado. Monografia (Graduação em Geografia) - FFP/UERJ: São Gonçalo, 2009.

DUSSEL, E. Europa, modernidade e eurocentrismo. In: LANDER, E. A colonialidade do saber: eurocentrismo e ciências sociais. Buenos Aires: CLASCO, 2005.

FREIRE, P. Pedagogia do Oprimido. Rio de Janeiro: Paz e Terra, 2005.

FERNANDES, B. M; MOLINA, M. C. O campo da educação do campo. In: MOLINA, M. C; JESUS, S. M. A. Por uma educação do campo. Vol. 5. Brasília, DF: Articulação Nacional "Por Uma Educação do Campo", 2004.

GOMES. P. C. C. Geografia e Modernidade. $6^{\mathrm{a}}$ Ed. Rio de Janeiro: Bertrand Brasil, 2007.

KROPOTKIN, Piotr. O que a geografia deve ser. In: VESENTINI, José William. Seleção

de textos ,13 -Teoria e Método. São Paulo: AGB-SP, 1986.

LACOSTE, Y. A geografia - isso serve, em primeiro lugar, para fazer a guerra.10 Ed. São Paulo: Papirus, 2005.

LANDER. E. Ciências sociais: saberes coloniais e eurocêntricos. In: LANDER, E. A colonialidade do saber: eurocentrismo e ciências sociais. Buenos Aires: CLASCO, 2005.

LEITE, S. C. Escola Rural: urbanização e políticas educacionais. 2ª Ed. São Paulo: Cortez, 2002. 


\section{REVISTA TAMOIOS}

MENDES, E. de P. P; MESQUITA, L. A. P. de. Geografia, educação rural e pertencimento: a valorização dos saberes e expressões culturais no ambiente escolar. Anais do XI - EREGEO- Simpósio regional de geografia. UFG - Campos Jataí, 2009.

MIGNOLO. W. D. A colonialidade de cabo a rabo: o hemisfério ocidental no horizonte conceitual da modernidade. In: LANDER, E. A colonialidade do saber: eurocentrismo e ciências sociais. Buenos Aires: CLASCO, 2005.

MOREIRA, R. Para onde vai o pensamento geográfico? Por uma epistemologia crítica. São Paulo: Contexto, 2008.

NABARRO, S. A; TSUKAMOTO, R. Y. Questão agrária e o livro didático de geografia: uma análise do conteúdo apresentado nos livros didáticos adotados pelas escolas de ensino fundamental da rede pública de Londrina - PR. Anais do XIX Encontro Nacional de Geografia Agrária. São Paulo, 2009.

OSLANDER. U. Espacio, lugar y movimientos sociales: hacia una "espacialidad de resistencia”. Universidad de Barcelona: Scripta Nova - Revista electrónica de geografia y ciencias sociales, 2002. Disponível em <http://www.ub.es/geocrit/sn/sn115.htm>. Acesso em 26 de abr. de 2010.

PATTO, M. H. S. A produção do fracasso escolar. São Paulo: T. A. Queiroz, 1990.

PORTO-GONÇALVES. C. W. Apresentação da edição em português In: LANDER, E. A colonialidade do saber: eurocentrismo e ciências sociais. Buenos Aires: CLASCO, 2005.

PORTO-GONÇÁLVES, C. W. A geograficidade do social: uma contribuição para o debate metodológico sobre estudos de conflito e movimentos sociais na América Latina. En publicación: SEOANE, J Movimientos sociales y conflictos en América Latina. Argentina: CLACSO, 2003.

SANTOS, B. S. Introdução a uma ciência pós-moderna. 3ª Ed. Rio de Janeiro: Graal, 2000.

SENE, E; MOREIRA, J. C. A geografia no dia-a-dia: 5ª série (Coleção Trilhas da geografia). São Paulo: Scipione, 2003.

SILVA, T. T. Projeto Educacional Moderno: Identidade Terminal? In: SILVA, T. T. Identidades Terminais. Petrópolis: Vozes, 1996. 


\section{REVISTA TAMOIOS}

VESENTINI, J. W; VLACH, S. Geografia Crítica. $2^{\circ}$ vol. $2^{\text {a }}$ Ed. São Paulo: Ática, 2007.

VESENTINI, J. W; DIAS, D. M; PÉCORA, M. Geografia. Vivência e Construção. $3^{\circ}$ vol. $2^{\text {a }}$ Ed. São Paulo: Ática, 2008. 